\title{
Hubungan Dimensi Metrik Ketetanggaan dan Dimensi Metrik Ketetanggan Lokal Graf Hasil Operasi Kali Korona
}

\author{
Virdina Rahmayanti ${ }^{1}$, Moh. Imam Utoyo ${ }^{2} \&$ Liliek Susilowati $^{3}$ \\ 1,2,3 Departemen Matematika, Fakultas Sains dan Teknologi, Universitas Airlangga
}

${ }^{3}$ Corresponding author: liliek-s@fst.unair.ac.id

\begin{abstract}
Adjacency metric dimension and local adjacency metric dimension are the development of metric dimension. The purpose of this research is to determine the adjacency metric dimension of corona graph between any connected graph $G$ and non-trivial graph $H$ denoted by $\operatorname{dim}_{\mathrm{A}}(G \odot H)$, to determine the local adjacency metric dimension of corona graph between any connected graph $G$ and non-trivial graph $H$ denoted by $\operatorname{dim}_{\mathrm{A}, \mathrm{l}}(G \odot H)$, and to determine the correlation between adjacency metric dimension and local adjacency metric dimension of corona product graph operations. In this research, it is found out that the value of adjacency metric dimension of $G \odot H$ graph is affected by the basic characteristic of $H$ and the domination characteristic. Meanwhile, the value of local adjacency metric dimension of $G \odot H$ graph is only affected by the basic characteristic of $H$. Futhermore, it is found a correlation of adjacency metric dimension and local adjacency metric dimension of corona product graph between any connected graph $G$ and non-trivial graph $H$.
\end{abstract}

Keywords: adjacency metric dimension, corona product graph, correlation of adjacency metric dimension, correlation of local adjacency metric dimension, local adjacency materic dimension.

\section{Pendahuluan}

Bagian dari teori graf yang terus berkembang adalah dimensi metrik. Konsep dimensi metrik diperkenalkan oleh Harary pada tahun 1976. Penelitian mengenai dimensi metrik telah dilakukan antara lain oleh Chartrand, et al. [1] yang menemukan beberapa karakterisasi dari dimensi metrik. Iswandi et al. [2] meneliti dimensi metrik graf yang mempunyai titik dengan derajat satu.

Selanjutnya, Jannesari dan Omoomi [3] mengembangkan konsep dimensi metrik menjadi dimensi metrik ketetanggaan. Pada tahun 2013, Rodriguez dan Fernau [4] menggabungkan konsep dimensi metrik lokal dan dimensi metrik ketetanggaan menjadi dimensi metrik ketetanggaan lokal.

Perkembangan dimensi metrik pada graf hasil operasi antara lain dimensi metrik ketetanggaan pada graf dengan operasi hasil kali korona oleh Rodriguez dan Fernau [4], dimensi metrik pada graf dengan operasi hasil kali comb oleh Saputro, dkk [5] dan 
keterkaitan antara dimensi metrik dan dimensi metrik lokal pada graf hasil operasi kali akar oleh Susilowati, dkk [6].

Dalam penelitian Rodriguez dan Fernau tahun 2013 [4] telah dibahas dimensi metrik ketetanggaan graf operasi hasil kali korona dan dimensi metrik ketetanggaan lokal graf hasil operasi kali korona. Dalam penelitian ini, dikaji ulang yang telah dihasilkan dalam jurnal Rodriguez dan melengkapi bukti dimensi metrik ketetanggaan dan dimensi metrik ketetanggaan lokal graf hasil operasi kali korona dengan menggunakan bahasa sendiri beserta hubungannya.

\section{Dimensi Metrik Ketetanggaan Graf Hasil Operasi Kali Korona}

Menurut Rodriguez dan Fernau [4], Untuk graf terhubung $G, N_{G}(w)$ adalah notasi yang menyatakan himpunan semua titik yang bertetangga dengan titik $w$ pada graf $G$. Himpunan $W$ adalah himpunan pembeda ketetanggaan (adjacency resolving set) jika untuk setiap dua titik $x, y \in V(G)-W$ terdapat $w \in W$ sedemikian sehingga $\left|N_{G}(w) \cap\{x, y\}\right|=1$. Himpunan pembeda ketetanggaan dengan kardinalitas minimum disebut basis metrik ketetanggaan untuk graf $G$ dan kardinalitasnya disebut dimensi metrik ketetanggaan yang dinotasikan $\operatorname{dim}_{A}(G)$. Akibatnya, kardinalitas minimal dimensi metrik ketetanggan adalah 1.

Misalkan $V(G)=\left\{v_{i} \mid i=1,2,3, \ldots, n\right\}$ dan $V(H)=\left\{u_{j} \mid j=1,2,3, \ldots, m\right\}$ dengan $n \geq 2$ dan $m \geq 2$. Titik pada graf $G \odot H$ terdiri atas dua bagian yaitu induk dan daun. Induk adalah titi-titik pada graf $G$ dan daun adalah titik-titik pada graf $H$. Induk dari graf $G \odot H$ dinotasikan dengan $G_{0}$ dengan $V\left(G_{0}\right)=\left\{v_{i 0} \mid v_{i} \in V(G)\right\}$. Salinan graf $H$ pada titik $v_{i}$ dengan $i=1,2,3, \ldots, n$ disebut daun ke- $i$ dan dinotasikan dengan $H_{i}$ dan $V\left(H_{i}\right)=$ $\left\{v_{i j} \mid u_{j} \in V(H)\right\}, i=1,2,3, \ldots, n$.

Teorema 2.1 Misalkan $G$ adalah sebarang graf terhubung berordo $n \geq 2$ dan $H$ adalah graf non-trivial. Jika terdapat basis ketetanggan $B$ dari $H$ dan merupakan himpunan dominasi, dan jika untuk setiap $v \in V(H)-B$ yang memenuhi $B \nsubseteq N_{H}(v)$, maka

$$
\operatorname{dim}_{A}(G \odot H)=n \cdot \operatorname{dim}_{A}(H) .
$$

Bukti. Misalkan $B_{i}$ adalah basis dari $H_{i}$.

Pilih $W=\bigcup_{i=1}^{n} B_{i}$. Diambil sebarang dua titik $x, y \in V(G \odot H)-W$ maka terdapat empat kemungkinan yaitu (i) $x, y \in V\left(H_{i}\right)$ (ii) $x \in V\left(H_{i}\right)$ dan $y \in V\left(H_{j}\right)$ dengan $i \neq j$ dan $i, j \in\{1,2,3, \ldots, n\}$, (iii) $x \in V\left(G_{0}\right)$ dan $y \in V\left(H_{i}\right)$, dan (iv) $x, y \in V\left(G_{0}\right)$. 
(i) Misalkan $x, y \in V\left(H_{i}\right)$. Karena $B_{i}$ adalah basis ketetanggaan dari $H_{i}$, terdapat $t \in S_{i}$ sehingga $t x \in E(G \odot H)$ dan $t y \notin E(G \odot H)$ atau $t x \notin E(G \odot H)$ dan ty $\in E(G \odot H)$ maka $\left|N\left(u_{i}\right) \cap\{x, y\}\right|=1$. Oleh karena itu $x, y$ memiliki pembeda ketetanggaan di $W$.

(ii) Misalkan $x \in V\left(H_{i}\right)$ dan $y \in V\left(H_{j}\right)$ dengan $i \neq j$. Karena $B_{i}$ adalah himpunan dominasi dari $H_{i}$, terdapat $t \in S_{i}$ sehingga $t x \in E(G \odot H)$ dan $t y \notin$ $E(G \odot H)$ maka $|N(t) \cap\{x, y\}|=1$. Oleh karena itu $x, y$ memiliki pembeda ketetanggaan di $W$.

(iii) Misalkan $x \in V\left(G_{0}\right)$ dan $y \in V\left(H_{i}\right)$. Terdapat $t \in S_{i}$ sehingga $t x \notin E(G \odot H)$ dan $t y \in E(G \odot H)$ maka $|N(t) \cap\{x, y\}|=1$. Oleh karena itu $x, y$ memiliki pembeda ketetanggaan di $W$.

(iv) Misalkan $x, y \in V\left(G_{0}\right)$. Terdapat $i, j \in\{1,2,3, \ldots, n\}$ dengan $i \neq j$ sehingga $x=v_{i}$ dan $y=v_{j}$. Dipilih $t \in B_{i}$. Karena $t v_{i} \in E(G \odot H)$ dan $t v_{j} \notin$ $E(G \odot H)$ maka $\left|N(t) \cap\left\{v_{i}, v_{j}\right\}\right|=|N(t) \cap\{x, y\}|=1$. Oleh karena itu $x, y$ memiliki pembeda ketetanggaan di $W$.

Berdasarkan uraian di atas diperoleh bahwa $W$ merupakan himpunan pembeda ketetanggaan $G \odot H$.

Selanjutnya, ditunjukkan bahwa $W$ merupakan himpunan pembeda ketetanggaan $G \odot H$ dengan kardinalitas minimal. Diambil sebarang $x \in W$, maka terdapat $i \in\{1,2,3, \ldots, n\}$, sehingga $x \in B_{i}$. Akan ditunjukkan bahwa $W \backslash\{x\}$ bukan himpunan pembeda ketetangaan. Karena $B_{i}$ adalah basis dari $H_{i}$, maka $B_{i} \backslash\{x\}$ bukan himpunan pembeda ketetanggaan dari $H_{i}$. Akibatnya terdapat dua titik $v_{i r}, v_{i t} \in V\left(H_{i}\right)-B_{i} \backslash\{x\}$ dengan $r \neq t$ sehingga untuk setiap $s \in B_{i} \backslash\{x\},\left|N(s) \cap\left\{v_{i r}, v_{i t}\right\}\right| \neq 1$. Diambil sebarang $s \in$ $W \backslash\{x\}$. Karena $v_{i r}, v_{i t} \in V\left(H_{i}\right)-B_{i} \backslash\{x\} \quad$ maka $v_{i r}, v_{i t} \in V(G \odot H)-W \backslash\{x\}$. Terdapat dua kemungkinan $s \in B_{i} \backslash\{x\}$ atau $s \in B_{j}$ dengan $j \neq i$.

(i) Misalkan $s \in B_{i} \backslash\{x\}$, berdasarkan uraian sebelumnya $\left|N(s) \cap\left\{v_{i r}, v_{i t}\right\}\right| \neq$ 1.

(ii) Misalkan $s \in B_{j}$ dan $v_{i r}, v_{i t} \in V\left(H_{i}\right)-B_{i} \backslash\{x\}$ dengan $i \neq j$, maka $\left|N(s) \cap\left\{v_{i r}, v_{i t}\right\}\right|=0 \neq 1$.

Berdasarkan kasus di atas, diperoleh bahwa $W$ merupakan himpunan pembeda ketetanggaan. Oleh karena itu, $W$ merupakan basis ketetanggaan dengan $\operatorname{dim}_{A}(G \odot H)=$ n. $\operatorname{dim}_{A}(H)$.

Teorema 2.2 Misalkan $G$ adalah sebarang graf terhubung berordo $n \geq 2$ dan $H$ adalah graf non-trivial. Jika terdapat basis ketetanggan dari $H$ yang merupakan himpunan dominasi, untuk setiap basis ketetanggaan $B$ di $H$ terdapat $v \in V(H)-B$ yang memenuhi $B \subseteq N_{H}(v)$, maka 


$$
\operatorname{dim}_{A}(G \odot H)=n \cdot \operatorname{dim}_{A}(H)+\gamma(G) .
$$

Bukti. Misalkan $B_{i}$ adalah sebarang basis ketetanggaan lokal dari $H_{i}$. $D=$ $\left\{v_{n_{k}} \mid k=1,2,3, \ldots, \gamma(G)\right\}$ merupakan himpunan dominasi dari graf $G$. Berdasarkan penamaan titik-titik hasil kali korona, $D_{0}=\left\{v_{n_{k} 0} \mid k=1,2,3, \ldots, \gamma(G)\right\} \subseteq G_{0}$.

Pilih $W=\bigcup_{i=1}^{n} B_{i} \cup D_{0}$. Diambil sebarang dua titik $x, y \in V(G \odot H)-W$ maka terdapat tiga kemungkinan yaitu (i) $x \in V\left(H_{i}\right)$ dan $y \in V\left(H_{i}\right)$ dengan $i \neq j$ dan $i, j \in$ $\{1,2,3, \ldots, n\}$, (ii) $x \in V\left(G_{0}\right)$ dan $y \in V\left(H_{i}\right)$ dengan $i \in\{1,2,3, \ldots, n\}$, dan (iii) $x, y \in$ $V\left(G_{0}\right)$.

(i) Misalkan $x \in V\left(H_{i}\right)$ dan $y \in V\left(H_{j}\right)$ terdadat $i, j \in\{1,2,3, \ldots, n\}$ dan $r, s \in$ $\{1,2,3, \ldots, m\}$ dengan $i \neq j$ dan $r \neq s$ sehingga $x=v_{i r}$ dan $y=v_{j s}$. Terdapat $v_{i t} \in W$ sehingga $v_{i t} v_{i r} \in E(G \odot H)$ dan $v_{i t} v_{j s} \notin E(G \odot H)$ maka $\mid N\left(v_{i t}\right) \cap$ $\left\{v_{i r}, v_{j s}\right\}|=| N\left(v_{i t}\right) \cap\{x, y\} \mid=1$. Oleh karena itu $x, y$ memiliki pembeda ketetanggaan di $W$.

(ii) Misalkan $x \in V\left(G_{0}\right)$ dan $y \in V\left(H_{i}\right)$ dengan $i \in\{1,2,3, \ldots, n\}$. Terdapat $v_{n_{k} 0} \in D_{0}$ sehingga $v_{n_{k} 0} x \in E(G \odot H)$ dan $\notin E(G \odot H)$ sehingga $\mid N\left(v_{n_{k} 0}\right) \cap$ $\{x, y\} \mid=1$. Oleh karena itu $x, y$ memiliki pembeda ketetanggaan di $W$.

(iii) Misalkan $x, y \in V\left(G_{0}\right)$ maka terdapat $i, j \notin\left\{n_{1}, n_{2}, n_{3}, \ldots, n_{\gamma(G)}\right\}$ dengan $i \neq$ $j$ sehingga $x=v_{i}$ dan $y=v_{j}$. Dipilih $v_{n_{k} 0} \in D_{0}$. Karena $v_{n_{k} 0} v_{i} \in E(G \odot H)$ dan $v_{n_{k} 0} v_{j} \notin E(G \odot H)$ maka $\left|N\left(v_{n_{k} 0}\right) \cap\left\{v_{i}, v_{j}\right\}\right|=\left|N\left(v_{n_{k} 0}\right) \cap\{x, y\}\right|=1$. Oleh karena itu $x, y$ memiliki pembeda ketetanggaan di $W$.

Berdasarkan uraian di atas diperoleh bahwa $W$ merupakan himpunan pembeda ketetanggaan $G \odot H$.

Selanjutnya, ditunjukkan bahwa $W$ merupakan himpunan pembeda ketetanggaan $G \odot H$ yang mempunyai kardinalitas minimal. Diambil sebarang $x \in W$. Akan ditunjukkan bahwa $W \backslash\{x\}$ bukan himpunan pembeda ketetanggaan. Terdapat dua kemungkinan yaitu terdapat $i \in\{1,2,3, \ldots, n\}$, sehingga $x \in B_{i}$ atau $x \in D_{0}$.

(i) Misalkan terdapat $i \in\{1,2,3, \ldots, n\}$, sehingga $x \in B_{i}$. Karena $B_{i}$ adalah basis dari $H_{i}$, maka $B_{i} \backslash\{x\}$ bukan himpunan pembeda dari $H_{i}$. Akibatnya terdapat dua titik $v_{i r}, v_{i t} \in V\left(H_{i}\right)-B_{i} \backslash\{x\}$ dengan $r \neq t$ sehingga untuk setiap $u \in$ $B_{i} \backslash\{x\},\left|N(u) \cap\left\{v_{i r}, v_{i t}\right\}\right| \neq 1$. Diambil sebarang $s \in W \backslash\{x\}$. Terdapat tiga kemungkinan, yaitu $s \in B_{i} \backslash\{x\}, s \in B_{j}$ dengan $j \neq i$ atau $s \in D_{0}$.

a. Misalkan $s \in B_{i} \backslash\{x\}$, berdasarkan kasus di atas maka $\mid N(s) \cap$ $\left\{v_{i r}, v_{i t}\right\} \mid \neq 1$. 
b. Misalkan $s \in B_{j}$. Karena $v_{i r}, v_{i t} \in V\left(H_{i}\right)-B_{i} \backslash\{x\}$ dengan $i \neq j$, maka $\left|N(s) \cap\left\{v_{i r}, v_{i t}\right\}\right|=0 \neq 1$.

c. Misalkan $s \in D_{0}$, maka terdapat $k \in\left\{1,2,3, \ldots, \gamma\left(G_{0}\right)\right\}$ sehingga $s=v_{p_{k} 0}$. Terdapat dua kemungkinan yaitu $p_{k} \neq i$ atau $p_{k}=i$. Untuk $p_{k} \neq i$ diperoleh bahwa $\left|N\left(v_{p_{k} 0}\right) \cap\left\{v_{i r}, v_{i t}\right\}\right|=0 \neq 1$ sebab $\quad v_{i r}, v_{i t} \in$ $V\left(H_{i}\right)-B_{i} \backslash\{x\}$, sedangkan untuk $p_{k}=i$ diperoleh bahwa $\mid N\left(v_{p_{k} 0}\right) \cap$ $\left\{v_{i r}, v_{i t}\right\} \mid=2 \neq 1$.

(ii) Misalkan $x \in D_{0}$. Karena $D_{0}$ adalah himpunan dominasi dari $G_{0}$, maka $D_{0} \backslash\{x\}$ bukan himpunan dominasi minimal dari $G_{0}$. Ada $u \in G_{0}$, sehingga untuk setiap $z \in D_{0} \backslash\{x\}, z$ tidak bertetangga dengan $u$. Karena $u \in G_{0}$, maka terdapat $i \in\{1,2,3, \ldots, n\}$ sehingga $u=v_{i 0}$. Dipilih $y \in V\left(H_{i}\right)-B_{i}$. Berdasarkan pemilihan $u$ dan $y$ diperoleh bahwa $u, y \in V(G \odot H)-W \backslash\{x\}$. Diambil sebarang $s \in W \backslash\{x\}$. Terdapat dua kemungkinan, yaitu $s \in D_{0} \backslash$ $\{x\}$ atau $s \in B_{i}$.

a. Misalkan $s \in D_{0} \backslash\{x\}$. Berdasarkan pemilihan $u$ dan $y$ diperoleh $|N(s) \cap\{x, y\}|=0 \neq 1$.

b. Misalkan $s \in B_{i}$. Berdasarkan pemilihan $u$ diperoleh $u s \in E(G \odot H)$, sedangkan $y s \in E(G \odot H)$ sebab $B_{i}$ merupakan basis dari $H_{i}$. Oleh karena itu $\left|N(s) \cap\left\{v_{i}, v_{i j}\right\}\right|=2 \neq 1$.

Berdasarkan kasus di atas, diperoleh bahwa $W$ merupakan himpunan pembeda ketetanggaan. Oleh karena itu, $W$ merupakan basis ketetanggaan dengan ketetanggaan lokal dengan $\operatorname{dim}_{A}(G \odot H)=n \cdot \operatorname{dim}_{A}(H)+\gamma(G)$.

\section{Dimensi Metrik Ketetanggaan Lokal Graf Hasil Operasi Kali Korona}

Untuk graf terhubung $G, N_{G}(s)$ adalah notasi yang menyatakan himpunan semua titik yang bertetangga dengan titik $s$ pada graf $G$. Himpunan $S$ adalah himpunan pembeda ketetanggaan lokal (local adjacency resolving set) jika untuk setiap dua titik yang bertetangga $x, y \in V(G)-S$ terdapat $s \in S$ sedemikian sehingga $\left|N_{G}(s) \cap\{x, y\}\right|=1$. Himpunan pembeda ketetanggaan lokal dengan kardinalitas minimum disebut basis metrik ketetanggaan lokal untuk graf $G$ dan kardinalitasnya disebut dimensi metrik ketetanggaan lokal yang dinotasikan $\operatorname{dim}_{A, l}(G)$. Akibatnya, kardinalitas minimal dimensi metrik ketetanggaan lokal adalah 1.

Misalkan $V(G)=\left\{v_{i} \mid i=1,2,3, \ldots, n\right\}$ dan $V(H)=\left\{u_{j} \mid j=1,2,3, \ldots, m\right\}$ dengan $n \geq 2$ dan $m \geq 2$. Titik pada graf $G \odot H$ terdiri atas dua bagian yaitu induk dan daun. Induk adalah titi-titik pada graf $G$ dan daun adalah titik-titik pada graf $H$. Induk dari graf $G \odot H$ dinotasikan dengan $G_{0}$ dengan $V\left(G_{0}\right)=\left\{v_{i 0} \mid v_{i} \in V(G)\right\}$. Salinan graf $H$ pada titik $v_{i}$ dengan $i=1,2,3, \ldots, n$ disebut daun ke- $i$ dan dinotasikan dengan $H_{i}$ dan $V\left(H_{i}\right)=$ $\left\{v_{i j} \mid u_{j} \in V(H)\right\}, i=1,2,3, \ldots, n$. 
Teorema 3.1 Misalkan $G$ adalah sebarang graf terhubung berordo $n \geq 2$ dan $H$ adalah graf non-trivial. Jika terdapat basis ketetanggan $B$ dari $H$ dan merupakan himpunan dominasi, dan jika untuk setiap $v \in V(H)-B$ yang memenuhi $B \nsubseteq N_{H}(v)$, maka

$$
\operatorname{dim}_{A l}(G \odot H)=n \cdot \operatorname{dim}_{A l}(H) .
$$

Bukti. Misalkan $B_{i}$ adalah sebarang basis ketetanggaan lokal dari $H_{i}$.

Pilih $W=\bigcup_{i=1}^{n} B_{i}$. Diambil sebarang dua titik yang bertetangga $x, y \in V(G \odot H)-W$ maka terdapat tiga kasus yaitu (i) $x, y \in V\left(H_{i}\right)$, (ii) $x, y \in V\left(G_{0}\right)$ dan (iii) $x \in V\left(G_{0}\right), y \in$ $V\left(H_{i}\right)$.

(i) Misalkan $x, y \in V\left(H_{i}\right)$. Karena $B_{i}$ adalah basis ketetanggaan lokal dari $H_{i}$ maka terdapat $\quad s \in B_{i} \subseteq W$ sehingga $|N(s) \cap\{x, y\}|=1$. Oleh karena itu $x, y$ memiliki pembeda ketetanggaan lokal di $W$.

(ii) Misalkan $x, y \in V\left(G_{0}\right)$ maka terdapat $i, j \in\{1,2,3, \ldots, n\}$ dengan $i \neq j$ sehingga $x=v_{i}$ dan $y=v_{j}$. Dipilih $s \in B_{i}$, karena $s v_{i} \in E(G \odot H)$ dan $s v_{j} \notin E(G \odot H)$ maka $\left|N(s) \cap\left\{v_{i}, v_{j}\right\}\right|=1$. Oleh karena itu $x, y$ memiliki pembeda ketetanggaan lokal di $W$.

(iii) Misalkan $x \in V\left(G_{0}\right)$ dan $y \in V\left(H_{i}\right)$. Karena $S_{i} \nsubseteq N_{H_{i}}(y)$, sehingga untuk setiap $s \in S_{i}-N_{H_{i}}(y)$ maka $s x \notin E(G \odot H)$ dan $s y \in E(G \odot H)$. Akibatnya, $|N(s) \cap\{x, y\}|=1$. Oleh karena itu $x, y$ memiliki pembeda ketetanggaan lokal di $W$.

Berdasarkan uraian di atas diperoleh bahwa $W$ merupakan himpunan pembeda ketetanggaan lokal $G \odot H$.

Selanjutnya, ditunjukkan bahwa $W$ merupakan himpunan pembeda ketetanggaan lokal $G \odot H$ dengan kardinalitas minimal. Diambil sebarang $x \in W$, maka terdapat $i \in$ $\{1,2,3, \ldots, n\}$, sehingga $x \in B_{i}$. Akan ditunjukkan bahwa $W \backslash\{x\}$ bukan himpunan pembeda ketetanggaan lokal. Karena $B_{i}$ adalah basis dari $H_{i}$, maka $B_{i} \backslash\{x\}$ bukan himpunan pembeda dari $H_{i}$. Akibatnya terdapat dua titik bertetangga $v_{i r}, v_{i t} \in V\left(H_{i}\right)-$ $B_{i} \backslash\{x\}$ dengan $r \neq t$ sehingga untuk setiap $s \in B_{i} \backslash\{x\},\left|N(s) \cap\left\{v_{i r}, v_{i t}\right\}\right| \neq 1$. Diambil sebarang $s \in W \backslash\{x\}$. Karena $v_{i r}, v_{i t} \in V\left(H_{i}\right)-B_{i} \backslash\{x\}$ maka $v_{i r}, v_{i t} \in V(G \odot H)-$ $W \backslash\{x\}$. Terdapat dua kemungkinan $s \in B_{i} \backslash\{x\}$ atau $s \in B_{j}$ dengan $j \neq i$.

(i) Misalkan $s \in B_{i} \backslash\{x\}$, berdasarkan uraian sebelumnya $\left|N(s) \cap\left\{v_{i r}, v_{i t}\right\}\right| \neq$ 1.

(ii) Misalkan $s \in B_{j}$ dan $v_{i r}, v_{i t} \in V\left(H_{i}\right)-B_{i} \backslash\{x\}$ dengan $i \neq j$, maka $\left|N(s) \cap\left\{v_{i r}, v_{i t}\right\}\right|=0 \neq 1$. 
Berdasarkan kasus di atas, diperoleh bahwa $W$ merupakan himpunan pembeda ketetanggaan lokal. Oleh karena itu, $W$ merupakan basis ketetanggaan lokal dengan $\operatorname{dim}_{A l}(G \odot H)=n \cdot \operatorname{dim}_{A l}(H)$.

Teorema 3.2 Misalkan $G$ adalah sebarang graf terhubung berordo $n \geq 2$ dan $H$ adalah graf non-trivial. Jika terdapat basis ketetanggan dari $H$ yang merupakan himpunan dominasi, untuk setiap basis ketetanggaan $B$ di $H$ terdapat $v \in V(H)-B$ yang memenuhi $B \subseteq N_{H}(v)$, maka

$$
\operatorname{dim}_{A l}(G \odot H)=n \cdot \operatorname{dim}_{A l}(H)+\gamma(G) .
$$

Bukti. Misalkan $D=\left\{v_{n_{k}} \mid k=1,2,3, \ldots, \gamma(G)\right\}$ merupakan himpunan dominasi dari graf $G$. Berdasarkan penamaan titik-titik hasil kali korona, $D_{0}=\left\{v_{n_{k} 0} \mid k=1,2,3, \ldots, \gamma(G)\right\} \subseteq$ $G_{0} . B_{i}$ adalah sebarang basis ketetanggaan lokal dari $H_{i}$.

Pilih $W=\cup_{i=1}^{n} B_{i} \cup D_{0}$. Diambil sebarang dua titik bertetangga $x, y \in V(G \odot H)-W$ maka terdapat tiga kemungkinan yaitu (i) $x, y \in V\left(H_{i}\right)$, (ii) $x, y \in V\left(G_{0}\right)$, dan (iii) $x \in$ $V\left(G_{0}\right)$ dan $y \in V\left(H_{i}\right)$.

(i) Misalkan $x, y \in V\left(H_{i}\right)$. Karena $B_{i}$ adalah basis ketetanggaan lokal dari $H_{i}$ maka terdapat $s \in B_{i} \subseteq W$ sehingga $|N(s) \cap\{x, y\}|=1$. Oleh karena itu $x, y$ memiliki pembeda ketetanggaan lokal di $W$.

(ii) Misalkan $x, y \in V\left(G_{0}\right)$ maka terdapat $i, j \notin\left\{n_{1}, n_{2}, n_{3}, \ldots, n_{\gamma(G)}\right\}$ dengan $i \neq$ $j$ sehingga $x=v_{i}$ dan $y=v_{j}$. Dipilih $t \in D_{0}$. Karena $t v_{i} \in E(G \odot H)$ dan $t v_{j} \notin E(G \odot H)$ maka $\left|N(t) \cap\left\{v_{i}, v_{j}\right\}\right|=|N(t) \cap\{x, y\}|=1$. Oleh karena itu $x, y$ memiliki pembeda ketetanggaan lokal di $W$.

(iii) Misalkan $x \in V\left(G_{0}\right)$ dan $y \in V\left(H_{i}\right)$ maka terdapat $i \notin\left\{n_{1}, n_{2}, n_{3}, \ldots, n_{\gamma(G)}\right\}$ dan $j \in\{1,2,3, \ldots, m\}$ sehingga $x=v_{i}$ dan $y=v_{j}$. Dipilih $t \in D_{0}$. Karena $t v_{i} \in E(G \odot H)$ dan $t v_{j} \notin E(G \odot H)$ maka $\left|N(t) \cap\left\{v_{i}, v_{j}\right\}\right|=\mid N(t) \cap$ $\{x, y\} \mid=1$. Oleh karena itu $x, y$ memiliki pembeda ketetanggaan lokal di $W$.

Berdasarkan uraian di atas maka $W$ merupakan himpunan pembeda ketetanggaan lokal graf $G \odot H$.

Selanjutnya, ditunjukkan bahwa $W$ merupakan himpunan pembeda ketetanggaan lokal $G \odot H$ yang mempunyai kardinalitas minimal. Diambil sebarang $x \in W$. Akan ditunjukkan bahwa $W \backslash\{x\}$ bukan himpunan pembeda ketetanggaan lokal. Terdapat dua kemungkinan yaitu terdapat $i \in\{1,2,3, \ldots, n\}$, sehingga $x \in B_{i}$ atau $x \in D_{0}$.

(i) Misalkan terdapat $i \in\{1,2,3, \ldots, n\}$, sehingga $x \in B_{i}$. Karena $B_{i}$ adalah basis dari $H_{i}$, maka $B_{i} \backslash\{x\}$ bukan himpunan pembeda dari $H_{i}$. Akibatnya terdapat 
dua titik bertetangga $v_{i r}, v_{i t} \in V\left(H_{i}\right)-B_{i} \backslash\{x\}$ dengan $r \neq t$ sehingga untuk setiap $u \in B_{i} \backslash\{x\},\left|N(u) \cap\left\{v_{i r}, v_{i t}\right\}\right| \neq 1$. Diambil sebarang $s \in W \backslash\{x\}$. Terdapat tiga kemungkinan, yaitu $s \in B_{i} \backslash\{x\}, s \in B_{j}$ dengan $j \neq i$ atau $s \in$ $D_{0}$.

a. Misalkan $s \in B_{i} \backslash\{x\}$, berdasarkan kasus di atas maka $\mid N(s) \cap$ $\left\{v_{i r}, v_{i t}\right\} \mid \neq 1$.

b. Misalkan $s \in B_{j}$. Karena $v_{i r}, v_{i t} \in V\left(H_{i}\right)-B_{i} \backslash\{x\}$ dengan $i \neq j$, maka $\left|N(s) \cap\left\{v_{i r}, v_{i t}\right\}\right|=0 \neq 1$.

c. Misalkan $s \in D_{0}$, maka terdapat $k \in\left\{1,2,3, \ldots, \gamma\left(G_{0}\right)\right\}$ sehingga $s=v_{p_{k} 0}$. Terdapat dua kemungkinan yaitu $p_{k} \neq i$ atau $p_{k}=i$. Untuk $p_{k} \neq i$ diperoleh bahwa $\left|N\left(v_{p_{k} 0}\right) \cap\left\{v_{i r}, v_{i t}\right\}\right|=0 \neq 1$ sebab $v_{i r}, v_{i t} \in V\left(H_{i}\right)-$ $B_{i} \backslash\{x\}$, sedangkan untuk $p_{k}=i$ diperoleh bahwa $\mid N\left(v_{p_{k} 0}\right) \cap$ $\left\{v_{i r}, v_{i t}\right\} \mid=2 \neq 1$.

(ii) Misalkan $x \in D_{0}$. Karena $D_{0}$ adalah himpunan dominasi dari $G_{0}$, maka $D_{0} \backslash\{x\}$ bukan himpunan dominasi minimal dari $G_{0}$. Ada $u \in G_{0}$, sehingga untuk setiap $z \in D_{0} \backslash\{x\}, z$ tidak bertetangga dengan $u$. Karena $u \in G_{0}$, maka terdapat $i \in\{1,2,3, \ldots, n\}$ sehingga $u=v_{i 0}$. Dipilih $y \in V\left(H_{i}\right)-B_{i}$. Berdasarkan pemilihan $u$ dan $y$ diperoleh bahwa $u, y \in V(G \odot H)-W \backslash\{x\}$. Diambil sebarang $s \in W \backslash\{x\}$. Terdapat dua kemungkinan, yaitu $s \in D_{0} \backslash\{x\}$ atau $s \in B_{i}$.

a. Misalkan $s \in D_{0} \backslash\{x\}$. Berdasarkan pemilihan $u$ dan $y$ diperoleh $|N(s) \cap\{x, y\}|=0 \neq 1$.

b. Misalkan $s \in B_{i}$. Berdasarkan pemilihan $u$ diperoleh $u s \in E(G \odot H)$, sedangkan $y s \in E(G \odot H)$ sebab $B_{i}$ merupakan basis dari $H_{i}$. Oleh karena itu $\left|N(s) \cap\left\{v_{i}, v_{i j}\right\}\right|=2 \neq 1$.

Berdasarkan kasus di atas, diperoleh bahwa $W$ merupakan himpunan pembeda ketetanggaan lokal. Oleh karena itu, $W$ merupakan ketetanggaan lokal dengan $\operatorname{dim}_{A l}(G \odot H)=n \cdot \operatorname{dim}_{A l}(H)+\gamma(G)$.

\section{Hubungan Dimensi Metrik Ketetanggaan dan Dimensi Metrik Ketetanggan Lokal pada Graf Operasi Hasil Kali Korona}

Hubungan dimensi metrik ketetanggaan graf $G \odot H$ dengan dimensi metrik ketetanggaan lokal graf $G \odot H$ diperoleh dari Teorema 4.1.1 dengan Teorema 4.2.1, hubungan tersebut disajikan dalam akibat berikut.

Akibat 4.3.1 Misalkan $G$ adalah sebarang graf terhubung berordo $n \geq 2$ dan $H$ adalah graf non-trivial. Jika terdapat basis ketetanggan $B$ dari $H$ dan merupakan himpunan dominasi, dan jika untuk setiap $v \in V(H)-B, B \nsubseteq N_{H}(v)$, maka 


$$
\frac{\operatorname{dim}_{A}(G \odot H)}{\operatorname{dim}_{A}(H)}=\frac{\operatorname{dim}_{A l}(G \odot H)}{\operatorname{dim}_{A l}(H)}
$$

Hubungan dimensi metrik ketetanggaan graf $G \odot H$ dengan dimensi metrik ketetanggaan lokal graf $G \odot H$ diperoleh dari Teorema 4.1.2 dengan Teorema 4.2.2, hubungan tersebut disajikan dalam akibat berikut.

Akibat 4.3.2 Misalkan $G$ adalah sebarang graf terhubung berordo $n \geq 2$ dan $H$ adalah graf non-trivial. Jika terdapat basis ketetanggan dari $H$ yang merupakan himpunan dominasi, untuk setiap basis ketetanggaan $B$ di $H$ terdapat $v \in V(H)-B$ yang memenuhi $B \subseteq N_{H}(v)$, maka

$$
\frac{\operatorname{dim}_{A}(G \odot H)-\operatorname{dim}_{A l}(G \odot H)}{\operatorname{dim}_{A}(H)-\operatorname{dim}_{A l}(H)}=|V(G)|
$$

\section{Kesimpulan}

Hasil yang diperoleh dari penelitian ini yaitu :

1. Dimensi metrik ketetangaan graf hasil operasi kali korona.

a. Dimensi metrik ketetanggaan graf hasil operasi kali korona dari graf terhubung $G$ dengan graf $H$ non-trivial adalah $\operatorname{dim}_{A}(G \odot H)=n \cdot \operatorname{dim}_{A}(H)$.

b. Dimensi metrik ketetanggaan graf hasil operasi kali korona dari gtaf terhubung $G$ dengan graf non-trivial $H$ adalah $\operatorname{dim}_{A}(G \odot H)=n \cdot \operatorname{dim}_{A}(H)+$ $\gamma(G)$.

2. Dimensi metrik ketetanggaan lokal graf hasil operasi kali korona.

a. Dimensi metrik ketetanggaan lokal graf hasil operasi kali korona dari graf terhubung $G$ dengan graf $H$ non-trivial adalah $\operatorname{dim}_{A l}(G \odot H)=n \cdot \operatorname{dim}_{A l}(H)$.

b. Dimensi metrik ketetanggaan lokal graf hasil operasi kali korona dari gtaf terhubung $G$ dengan graf non-trivial $H$ adalah $\operatorname{dim}_{A l}(G \odot H)=$ $n \cdot \operatorname{dim}_{A l}(H)+\gamma(G)$.

3. Hubungan dimensi metrik ketetangaan dengan dimensi metrik ketetanggaan lokal graf hasil operasi kali korona adalah.

a. Hubungan dimensi metrik ketetanggaan lokal graf hasil operasi kali korona dari graf terhubung $G$ dengan graf non-trivial $H$ dengan basis dari $H$ merupakan himpunan dominasi adalah

$$
\frac{\operatorname{dim}_{A}(G \odot H)}{\operatorname{dim}_{A}(H)}=\frac{\operatorname{dim}_{A l}(G \odot H)}{\operatorname{dim}_{A l}(H)} .
$$

b. Hubungan dimensi metrik ketetanggaan lokal graf hasil operasi kali korona dari graf terhubung $G$ dengan graf non-trivial $H$ dengan basis dari $H$ merupakan himpunan dominasi adalah

$$
\frac{\operatorname{dim}_{A}(G \odot H)-\operatorname{dim}_{A l}(G \odot H)}{\operatorname{dim}_{A}(H)-\operatorname{dim}_{A l}(H)}=|V(G)| .
$$




\section{Daftar Pustaka}

[1] Chartrand, G. dan Lesniak, L., 2000, Graph and Digraph, Third Edition, Chapman \& Hall/CRC. Florida.

[2] Iswandi, H., Baskoro, E.T., dan Simanjuntak, R., 2011. On The Metric Dimension of Corona Product of Graph, Far East Journal of Mathematical Sciences (FJMS), 52(2): 155-170.

[3] Jannesari, M. dan Omoomi, B., 2012, The Metric Dimension of Lexicographic Product of Graphs, Discrete Mathematics, Volume 312, Number 22, pp. 33493356.

[4] Rodriguez-Velazquez, J. A. dan Fernau, H., 2013, On the (adjacency) metric dimension of corona and strong product graphs and their local variants, combinatorial and computational results.

[5] Saputro, S. W., Mardiana, N. dan Purwasih, I. A., 2013, The Metric Dimension of Comb Product Graphs, Graph Theory Conference in honor of Egawa's 60th birthday.

[6] Susilowati, L., Salamin, Utoyo, M. I. dan Estuningsih, N., 2015, The Similarity of Metric Dimension and Local Metric Dimension of Rooted Product Graph, Far East Journal of Mathematical Sciences (FJMS), Volume 97, Number 7, 2015, Pages 841-856. 